\title{
A política externa cubana nos anos \\ 90: condicionantes internos e inserção internacional
}

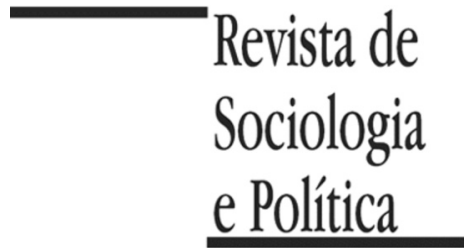

\author{
Marcos Antonio da Silva, Guillermo Alfredo Johnson e Anatólio Medeiros Arce
}

\begin{abstract}
RESUMO
O presente trabalho analisa a política externa cubana nos anos 90, depois do colapso do bloco soviético, que conduziu o país a mais grave crise econômica de sua história recente e a um relativo isolamento internacional, elementos que foram determinantes para sua reinserção internacional. A partir disto aponta que sua reinserção internacional se fundamenta na afirmação da soberania nacional, na ampliação dos atores envolvidos na formulação e execução de tal política, na busca de novos parceiros que conduziu a uma inserção pendular no cenário internacional e no desenvolvimento da diplomacia social. A pesquisa foi realizada através de levantamento e análise bibliográfica, bem como de dados indicativos da situação econômica do país e de sua inserção internacional, combinando elementos de análise quantitaviva com a qualitativa. A hipótese inicial fundamenta-se na reorientação da política externa cubana, com o fim do bloco soviético, e na sua reinserção, embora tensa, no cenário internacional determinadas pela crise interna e pelo novo contexto internacional. O levantamento de dados foi possível através de pesquisas in loco e em portais e publicações de organismos como a CEPAL (Comissão Econômica para a América Latina) e ONEl (Oficina Nacional de Estadistica y Informaciones), assim como de autores dedicados ao tema. Através de análise crítica e comparativa de tais dados e informações estabelece as variáveis fundamentais e os elementos que permitem a compreensão da política externa cubana no período mencionado. Tal trabalho demonstra que a política externa cubana foi resultado da interação entre os fatores domésticos, a crise econômica e social que o país enfrentou, e de fatores internacionais. Além disto, aponta que ocorreu uma reorientação da política externa cubana com o desenvolvimento de novas estratégias e parcerias para sua reinserção internacional. Finalmente, demonstra que tal política obteve um sucesso relativo, pois permitiu uma parcial recuperação econômica e a manutenção do regime. O artigo contribui para o conhecimento da realidade interna e da inserção internacional de Cuba no novo contexto internacional, aspectos relativamente ignorados na academia brasileira e propicia novos elementos para compreensão dos aspectos determinantes da política externa dos Estados no contexto da globalização.
\end{abstract}

PALAVRAS-CHAVE: Política Externa; Cuba; Diplomacia Social; Condicionantes; Inserção Internacional Recebido em 2 de Agosto de 2012. Aprovado em 12 de Novembro de 2012.

\section{Introdução}

\footnotetext{
${ }^{1}$ Versões deste texto foram apresentadas no $3^{\circ}$ Encontro Nacional da Associação Brasileira de Relações Internacionais (ABRI) e no $3^{\circ}$ Seminário Nacional Sociologia \& Política (UFPR). Agradecemos aos pareceristas da Revista de Sociologia e Política pelas pertinentes observações e sugestões.
}

A Revolução Cubana foi um acontecimento fundamental para a América Latina e, de certa forma, para as relações internacionais na segunda metade do século $\mathrm{XX}^{1}$.

Durante várias décadas, o processo revolucionário cubano determinou o conjunto das relações internacionais do país e, ainda, tornou-se um marco nas relações regionais e na política doméstica de vários países latino-americanos. Não era possível a indiferença em relação ao que acontecia em Cuba e a atuação externa do país, em prol de transformações radicais na região. Além disso, o cenário internacional, marcado pela Guerra Fria, tornava a ilha e sua atuação um elemento importante no sistema internacional e nas relações interamericanas. Esse cenário modificou-se, até abruptamente, no início da década de 1990, com a queda do bloco soviético e a desintegração da União das Repúblicas Socialistas Soviéticas (URSS). Com o fim do socialismo soviético, inúmeras 
dúvidas pairavam sobre o destino cubano: qual o impacto e o que aconteceu com Cuba depois da queda do bloco soviético? Que mudanças políticas e econômicas ocorreram no país na década de 1990? Como Cuba reorientou sua política externa para superar o isolamento internacional?

Quando visitou Cuba no início da década de 1960, Jean-Paul Sartre criou uma metáfora para descrever o desenvolvimento do processo revolucionário. Utilizando-se de uma imagem comum ao Caribe, o filósofo francês apontava que um furacão havia passado pela ilha, demonstrando com isso, os processos de transformação da velha ordem capitalista e de instauração da sociedade socialista, que revolucionava todos os aspectos da vida social: da educação à política, da economia à cultura, da posse pela terra ao lazer, da saúde ao esporte e assim por diante (Sartre 1986). Na década de 1990, o país enfrentou um novo (e inesperado) furacão. A queda do Muro de Berlim e a derrocada do socialismo real no Leste Europeu provocaram uma reviravolta no processo de construção do socialismo cubano. De forma abrupta, o país perdeu contato com um mercado que representava cerca de $85 \%$ de seu comércio exterior. Esgotaram-se as fontes de financiamento e os benefícios em preços e subsídios fornecidos por tal bloco. Cessaram as fontes de fornecimento de petróleo. $\mathrm{O}$ resultado foi o quase colapso econômico e o aumento dos problemas sociais. Grande parte das atividades foi paralisada, a produção econômica em todos os setores caiu enormemente, os transportes foram paralisados e o nível de vida decresceu.

Tal cenário exigia uma redefinição da política externa cubana e combinava desafios a serem superados, mas também oportunidades, que poderiam contribuir para a sobrevivência das mudanças desenvolvidas pelo país. Para tanto, era fundamental o desenvolvimento de uma estratégia adequada (e cuidadosa).

O presente trabalho procura analisar tal estratégia, discutindo a política externa de Cuba na década de 1990. Para tanto, organiza-se da seguinte forma: em um primeiro momento, analisa os impactos do fim do socialismo real, interna e externamente. Em seguida, discute os principais aspectos da política externa desenvolvida pelo país no cenário de incerteza. Finalmente, apresenta as principais conclusões.

\section{Cuba e a eterna guerra-fria: os impactos do fim do socialismo real}

A relação Cuba-URSS, demonstrada com os dados anteriores, foi argutamente captada pela definição de Alfonso (1998) que denomina este período de

${ }^{2}$ Bandeira (1996) apresenta uma análise interessante de tal relação e a caracteriza, aproveitando-se de um conceito reconhecido na América Latina e sua inserção internacional, como "socialismo dependente"

\footnotetext{
${ }^{3}$ Entre eles podemos destacar a aceitação da divisão internacional proposta pelo Consejo de Ayuda Mutua Económica (CAME) e a manutenção de uma economia agrário-exportadora; a perseguição a membros de seitas religiosas; a adoção do planejamento centralizado em condições adver-
} utopia "subsidiada". Segundo ele, a realização dos dois objetivos básicos da revolução socialista cubana, a nivelação e a mobilidade social, acabaram mostrando a contradição e os limites do projeto cubano. O primeiro teve como ponto de partida o radicalismo dos anos 1960, levando a virtual liquidação dos setores burgueses e de boa parte da classe média por meio do predomínio de formas sociais e estatais de propriedade dos meios de produção, muitas vezes através da incorporação acrítica dos mecanismos adotados nos países do socialismo real ${ }^{3}$. Aliado a isso, o segundo objetivo foi caracterizado pela mobilidade ascendente das maiorias, principalmente nos anos 1970, apoiado em programas estatais de provisão de empregos e de serviços sociais que alcançavam a maioria absoluta da população.

Tais objetivos foram desenvolvendo-se com base em duas categorias sociais, que impediam o auto-reconhecimento das identidades setoriais mesmo quando as condições objetivas conduziam a uma diferenciação, fundadas nos 
sas e o modelo leninista de partido, entre outros (Alfonso 1998). conceitos de povo e vanguarda. No primeiro, reconhecia-se a grande maioria da sociedade que atuava como o veículo sociopolítico de transformação social e de defesa nacional; no segundo, estavam os grupos organizados no seio do Partido Comunista Cubano, que orientavam e conduziam as transformações. Tal distinção, segundo Alfonso (idem), toma como base o modelo leninista de organização e sua consequência mais imediata é a reprodução dos vícios e das contradições do socialismo real, principalmente no que se refere à concentração de poder.

Isso significa que a classe política revolucionária exerceu o poder em condições quase monopolistas em pelo menos três dimensões. Em primeiro lugar, na atribuição de recursos por meio de uma planificação centralizada, aprofundada nos anos 1970, que garantiu um crescimento extensivo com recursos relativamente abundantes, apoiados pelos subsídios soviéticos, mas com base em uma produção pouco exigente, uma distribuição equitativa e um consumo subsidiado. Em segundo lugar, a adoção do modelo leninista de organização política foi constituída por um sólido mecanismo de controle político, não só em relação à repressão das tendências antissistema, mas principalmente em relação à mobilização e à socialização de valores e condutas políticas. Finalmente, a produção de uma ideologia crível e legitimadora, operando como um paradigma teleológico, que gerava unidade e certeza enfatizando a relação entre o existente, o melhor e o possível, bem como enfatizando valores da cultura nacional como os princípios éticos da política, o patriotismo, o internacionalismo e a equidade social, entre outros, que podiam ser facilmente compreendidos pelo cidadão comum.

O resultado foi que: "Entretanto, este esquema continha sérias contradições originadas dos seus propósitos declarados de socialização do poder e a sua apropriação paulatina por uma camada burocrática emergente durante os anos 60 e definitivamente consolidada na década seguinte, à sombra do chamado processo de institucionalização. Em termos sistêmicos, a consolidação do estamento burocrático só pode ser conseguida a partir da extensão de relações clientelistas-paternalistas, da detenção do processo de socialização do poder e, por conseguinte, do congelamento do desenvolvimento socialista do projeto. A história ocupou-se em mostrar tanto as virtudes quanto os inconvenientes deste tipo de ordenamento de regulação sociopolítica" (idem, p. 131).

Dessa forma, tal estratégia política foi eficaz ao promover uma distribuição equitativa dos recursos disponíveis, facilitando a mobilização, promovendo uma cultura política solidária e permitindo o êxito parcial no enfrentamento de um inimigo externo poderoso, porém manteve o caráter dependente da economia cubana e, mais importante, contribuiu para a sua obsolescência, principalmente quando a mobilidade e a alta qualificação começaram a chocar-se com a rigidez dos mecanismos de controle sociopolíticos contribuindo, segundo o autor, para produzir certas disfunções e para a emergência do mercado, nos anos 1990 como ator destacado de remodelação de recursos e distribuição do magro excedente e das relações de poder.

O fim do bloco soviético atingiu profundamente Cuba, devido aos intensos laços que foram gestados entre o país e a comunidade socialista desde a Revolução Cubana, em 1959. Tais laços profundos haviam determinado grande parte da organização econômica, política e social do país (Salazar 1997; Bandeira 1998; Sader 2001; Ayerbe 2004). O rompimento involuntário e inesperado gerou, no mínimo, duas consequências imediatas. 
${ }^{4}$ Esses e outros dados são aproximados e baseados em estatísticas da Comisión Económica para América Latina (Cepal), de organismos nacionais e internacionais e de "cubanólogos". Como aponta Mesa-Lago (1998), inúmeros fatores dificultam a análise de dados efetivos: até 1989 muitos dados eram baseados no Produto Social Global (PSG), utilizados por países socialistas e que não é comparável ao Produto Interno Bruto (PIB); nos anos 1990 interrompeu-se a produção do "Anuário Estatístico" que fornecia uma visão geral da economia e sociedade cubanas; muitos produtos fornecidos pela URSS e seus preços eram distorcidos; finalmente, por se tratar de uma economia fechada, a taxa de câmbio pode apresentar distorções.

${ }^{5}$ Como aponta a Cepal: "La magnitud del shock económico ha sido comparable al registrado en Europa Oriental o en la antigua Unión Soviética, aunque sus características específicas difieran substancialmente" (CEPAL 2000, p. 16).
No plano interno, o país enfrentou uma profunda crise econômica e social, iniciando uma nova etapa na sua história, denominada oficialmente de "Período Especial em Tempos de Paz". Tal crise atingiu todos os setores do país, afetando a produção e o intercâmbio comercial, além de atingir o plano social.

Para ter-se uma ideia de sua profundidade é preciso considerar alguns dados. No âmbito econômico, como aponta Mesa-Lago (1998) que aponta os efeitos das mudanças analisando a variação de elementos essenciais na economia, no setor externo e nas condições sociais desde a interrupção da contribuição soviética e do CAME ${ }^{4}$.

Inúmeros indicadores destacam-se na tabela 1. Inicialmente, pode-se apontar o impacto ${ }^{5}$ do fim do bloco soviético sobre a economia cubana, como também destaca Almendra (1998), em 1989, Cuba havia recebido de ajuda soviética cerca de US\$ 6 bilhões, que eram investidos em setores como saúde, educação, transportes e defesa, sendo que este consumia aproximadamente US \$1,3 bilhão. Essa ajuda significava 30\% do PIB cubano. Em 1992, a ajuda havia caído a zero, atingindo de forma drástica os programas desenvolvidos nesses setores, mas, principalmente, o setor militar, em que eram destinados cerca de $20 \%$ dos subsídios recebidos, sem contar o fornecimento gratuito de vários materiais militares (Almendra 1998; Mesa-Lago 1998; CEPAL 2000).

A ausência deste apoio representou um duro golpe na economia cubana. $\mathrm{O}$ PIB cubano encolheu entre $40 \%$ e 50\% nesse período, ou seja, o país sofreu uma redução de sua economia desta ordem (Almendra 1998; Mesa-Lago 1998; Cepal 2000). Ainda, o país também passou a enfrentar problemas relacionados a ausência de capitais, o que incrementou a dívida cubana; no início dos anos 1980, o país tinha dívidas na ordem de US\$ 2 bilhões, que foram aumentando progressivamente até chegar ao montante de US\$10,8 bilhões, em 1993.

Outro indicador significativo refere-se ao encolhimento do comércio externo cubano que, como afirmamos anteriormente, era altamente concentrado e dependente do mercado socialista. Como se pode observar, as exportações cubanas caíram de um total de US\$ 5,4 bilhões em 1989 para apenas US\$ 1,1 bilhão em 1993, prejudicando o investimento e o gasto público, provocando uma deterioração da produção e dos serviços. Da mesma forma, as importações decresceram de US $\$ 8,1$ bilhões, em 1989, para cerca de US\$ 2 bilhões em 1993, o que significa uma redução de quase $70 \%$, afetando diretamente o consumo e a produção, reduzindo o mercado interno cubano na mesma medida (Almendra 1998; Mesa-Lago 1998; CEPAL 2000).

Portanto, podemos observar que tal opção gerou uma situação em que, ao final dos anos 1980, mais de $85 \%$ do intercâmbio comercial cubano estava vinculado ao CAME e, ainda no início dos anos 1990, cerca de $40 \%$ dos alimentos de consumo, além do petróleo a preço preferencial, eram importados da URSS. O resultado foi desastroso, pois essa aproximação levou o país a perpetuar o atraso tecnológico e a manter um nível de produtividade mais baixa em relação aos países ocidentais, apesar da qualificação de sua mão-deobra. Quando esses laços se rompem, o comércio internacional cubano ficaria reduzido a cerca de 30\% do que era antes (Almendra 1998; Mesa-Lago 1998; CEPAL 2000).

Emblemático, nesse sentido, é o caso do açúcar, pois representava a base da produção e o melhor dos recursos cubanos, possuindo um alto valor simbólico para o país. O papel desempenhado pelo país na divisão do trabalho proposta pelo CAME acentuou determinadas tendências históricas, anteriores à 
Tabela 1 - Desempenho da economia cubana, 1989-1995 (em milhões de pesos)

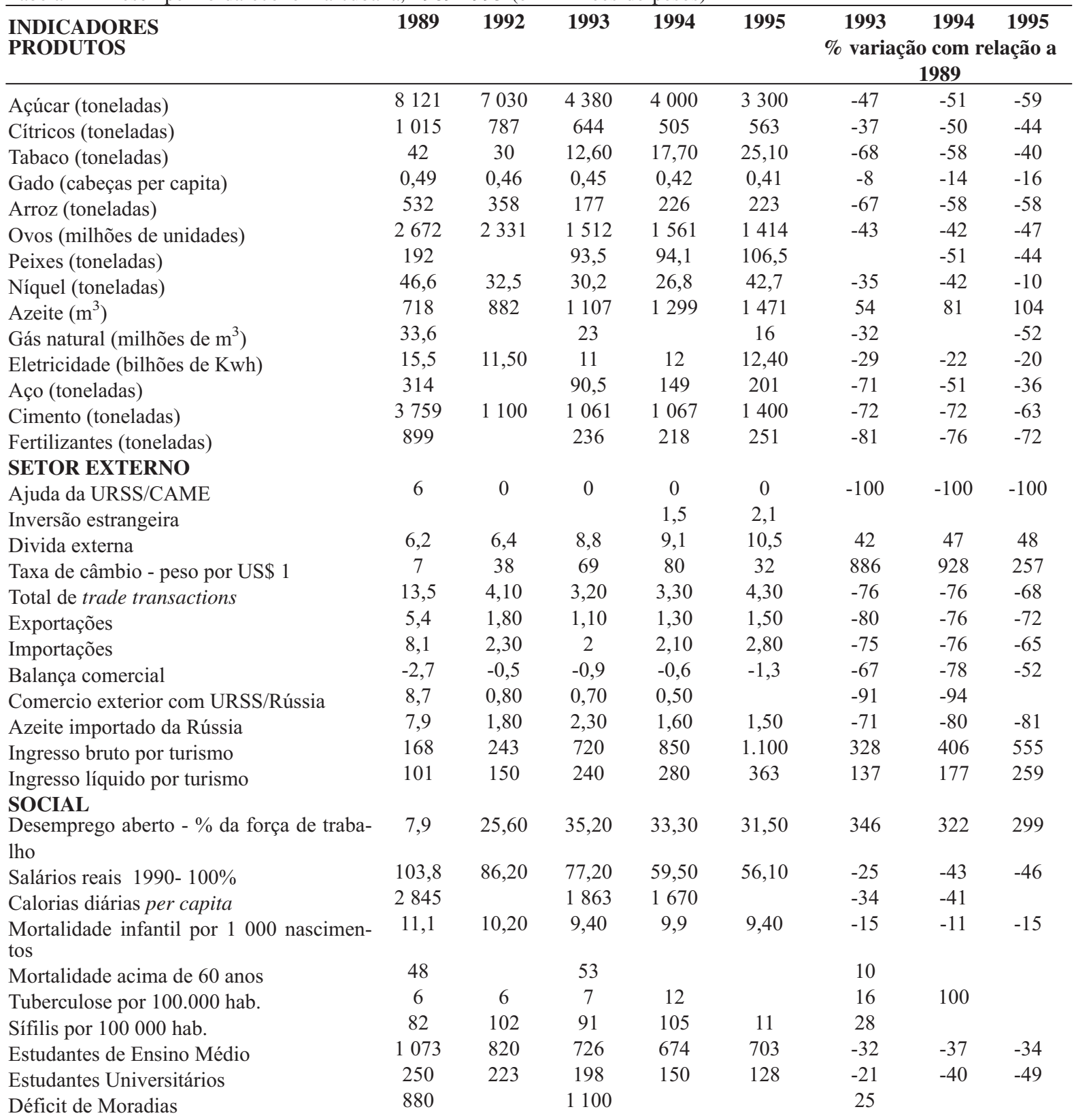

Fonte: Mesa-Lago (1998, p. 25; tradução dos autores).

Revolução. Antes desta, o país havia se especializado na produção do açúcar, o que acentuava o caráter monoprodutor e monoexportador de sua economia. Essa relação mantém-se com a ligação à URSS.

A produção açucareira, que entre 1989-1090 era próxima a 8 milhões de toneladas, e cuja média, entre 1981 e 1990, era de 7,7 milhões, caiu para 7 milhões em 1992, a 4,3 milhões em 1993, a 4 milhões em 1994 e a 3,5 milhões em 1995, a mais baixa em 50 anos. Apesar de aumentar para 4,4 milhões em 1996, essa média foi a sexta mais baixa em 40 anos. Além disso, o preço do açúcar no mercado mundial também estava em queda devido à produção, entre outros, de Brasil e Austrália. Ainda, a prioridade que a produção e a comercia- 
lização do açúcar desempenharam na economia cubana fez com que o ciclo vicioso estendesse-se a outros setores da economia (Almendra 1998; MesaLago 1998; CEPAL 2000).

A crise econômica e o ajuste que se seguiu também atingiram parcialmente as conquistas sociais da revolução. Depois de 1959, Cuba conseguiu níveis de pleno emprego, assistência sanitária, pensões e igualdade social acima dos países socialistas e da América Latina. Como aponta Mesa-Lago (1998), a crise obrigou o fechamento de $70 \%$ das indústrias, do maior complexo niqueleiro, e de $90 \%$ dos transportes de Havana e outras cidades, além da volta de tropas cubanas da África e outros lugares, assim como do pessoal civil.

A crise econômica também atingiu, embora não tenha provocado um retrocesso definitivo e que possa equiparar-se ao período pré-revolucionário, duas das maiores conquistas da Revolução, a saúde e a educação. Em relação à primeira, houve um aumento de problemas relacionados à mortalidade acima dos 60 anos, a tuberculose, que duplicou, e a sífilis, que aumentou em 50\%, embora seja necessário destacar que ocorreu uma queda da mortalidade infantil, em que o país possui níveis comparados ao dos países desenvolvidos sendo de 9,4 por 1000 nascimentos em 1995; além disso, a crise causou a falta de 300 tipos de medicamentos, vacinas, material cirúrgico e peças para equipamentos médicos, que, aliados à redução do consumo de alimentos, afetaram duramente o setor. Mesmo que, como aponta o governo, nenhum hospital tenha sido fechado e da continuada queda da mortalidade infantil, as condições de saúde se deterioram. No primeiro semestre de 1993, houve uma epidemia de neurose ótica, causada em grande medida pela má nutrição e deficiências de vitaminas (Almendra 1998; Mesa-Lago 1998).

Também na educação a crise gerou impactos. Por um lado, houve uma escassez de papel, lápis, livros e outros materiais didáticos e pedagógicos; além da deterioração dos prédios públicos e materiais utilizados para atividades desportivas e artísticas que eram substituídos de maneira criativa, embora algumas vezes inadequadas. De outro lado, como nos mostra Mesa-Lago (1998), ocorreu uma diminuição do número de estudantes matriculados: no ensino médio, o número de matriculas decresceu de 1,073 milhão de alunos, em 1989, para 703 mil alunos em 1995, uma queda de 34\%; no ensino superior a queda foi ainda mais intensa, caindo de 250 mil, em 1989, para cerca de 128 mil em 1994, uma queda de quase 50\%. Como apontou Raul Castro, citado por Mesa-Lago (1998), isso ocorreu, em grande medida, devido à perda de perspectivas de inserção no mercado de trabalho e pelo fato de que muitos trabalhadores autônomos conseguem rendimentos melhores do que os que possuem diploma universitário.

Finalmente, a crise econômica desenvolveu um novo fluxo migratório. Ao longo de sua história, Cuba presenciou pelo menos três ondas migratórias com características específicas. As duas primeiras, nos anos 1960 e 1980 foram motivadas, basicamente, por razões ideológicas seja de discordância com as medidas do regime recém-instalado (principalmente por membros da classe média e alta que tiveram seus benefícios atingidos pelas primeiras medidas da Revolução), seja por divergência com os seus rumos, como no caso de Mariel (década de 1980). A nova onda migratória, diferentemente das anteriores, foi motivada pela da qualidade de vida, pela queda da renda per capita e da qualidade dos serviços essenciais, gerando o fenômeno dos "balseros", como se observou no chamado verano caliente, em 1992. Em agosto de 1994, mais de 35 mil pessoas tentaram cruzar o estreito que separa Cuba dos EUA em precá- 
rias embarcações - os balseiros - obrigando o governo americano a rever sua política de "portas abertas" a refugiados cubanos.

Além dos problemas internos, o impacto do fim da URSS atingiu diretamente a inserção internacional do país. Desse modo, Cuba perdeu o principal parceiro, econômico e militar. Além disso, viu nascer uma ordem internacional hegemonizada pelo seu principal oponente, que se tornou a única superpotência mundial, mantendo uma política de isolamento e embargo ao país, para provocar a queda do regime cubano e desenvolvendo uma hegemonia que adquiriu cada vez mais contornos imperiais. Diante disso, o país encontrou-se mais indefeso e isolado, desde que se iniciou o processo de construção do socialismo na década de 1960 e, diante da ausência de uma comunidade sólida com quem estabelecer laços, teve de enfrentar um duplo desafio. Por um lado, como analisamos anteriormente, o país precisou enfrentar uma crise de legitimidade que afetava o regime, depois da crise dos referenciais políticos que orientaram a construção de sua estrutura socialista; e, por outro, o crescente isolamento e a dificuldade de inserir-se nesse mundo novo que se inaugurava (Ikenberry 2002; Ayerbe 2004).

\section{A política externa cubana na década de 1990: isolamento ou reinserção?}

Diante dos desafios impostos por essas mudanças, o país viu-se obrigado a adequar seu aparato produtivo, institucional e legal às novas condições que lhe foram impostas e, principalmente, reconstruir todo seu sistema de relações externas. Para tanto, foi necessário redefinir os princípios, os objetivos e a dinâmica de sua política externa.

Sendo assim, o objetivo fundamental que orientou tal política foi o desenvolvimento de ações e relações que pudessem garantir a sobrevivência do regime, diante da queda do bloco soviético. Essa dinâmica de sobrevivência já aparecia nos anos anteriores e estava relacionada, sobretudo, à consolidação das mudanças desenvolvidas pelo regime da revolução. Nos anos 1990, porém, modificam-se a sua natureza e seu impacto sobre a política externa do país. Primeiro, por ser absolutamente necessário o reordenamento das relações econômicas do país e, junto a isso, a realização de mudanças para garantir a previsibilidade e, acima de tudo, a confiança da comunidade internacional e dos parceiros bilaterais nos negócios que poderiam ser realizados. Além disso, o cenário econômico interno condicionava, em maior ou menor medida, a busca de parceiros que pudessem investir e suprir as necessidades do país.

A concretização dessa estratégia de sobrevivência só poderia ser eficaz na medida em que o país fosse capaz de superar o isolamento, econômico e político, a que se viu submetido. Grande parte dos elementos de isolamento do país tinha relação direta com a Guerra Fria, sendo uma herança do posicionamento do país e da esperança de que as relações com a comunidade socialista não seriam rompidas. Dessa forma, o país foi excluído do seio da Organização dos Estados Americanos (OEA), ainda em 1962, e pouco a pouco foi abandonando qualquer tentativa de retorno, o que não era uma prioridade para a liderança do país, seja devido à percepção de que a entidade era determinada pelo peso e influência norte-americana, seja porque foi possível, embora nem sempre de forma adequada e estável, a manutenção dos laços com os países da região, principalmente no caso de governos simpáticos à causa cubana, como também a partir do processo de democratização que permitiu a superação dos entraves ideológicos, de ambos os lados, para o estabelecimento de relações políticas 
maduras com a maioria dos países. Além disso, o país retirou-se do Fundo Monetário Internacional (FMI) e do Banco Mundial, sendo que nunca fez parte do Banco Interamericano de Desenvolvimento (BID) (Domínguez 2004b).

Além disso, deve-se considerar que esse isolamento possuía um aspecto econômico, derivado dos problemas de sua estrutura produtiva, em geral atrasada, e dos poucos produtos que o país poderia fornecer ao mercado internacional, já que se especializara na divisão anterior, condicionada pela comunidade socialista.

Para que isso fosse alcançado ocorreu, conforme aponta Alzugaray (2003), sob outra perspectiva, uma redefinição do interesse nacional cubano. Tal interesse nacional havia sido orientado, até então, pela manutenção da segurança e do desenvolvimento do país, como apontou-se anteriormente, ao analisar o processo de consolidação da Revolução, daí a importância fundamental da aliança com a URSS. Tal política, apesar de promover o rompimento do isolamento diplomático, de contribuir para o estabelecimento de laços em todos os continentes, inclusive com países próximos dos EUA, e garantir um papel ativo nas lutas do Terceiro Mundo, manteve, porém, o país vulnerável e dependente, o que se mostrou extremamente problemático com o fim da ordem em que fora gerado. Desse modo, o interesse nacional, definido no contexto da Guerra Fria, já não era possível e eficaz.

Sendo assim, Alzugaray (idem) aponta que ocorreu uma redefinição do interesse nacional. Considerando os fundamentos políticos e ideológicos que, segundo ele, propiciaram a sedimentação de um pensamento radical, progressista e emancipador em Cuba, cuja figura maior foi José Martí, que antecedem e são apropriados pela Revolução Cubana e sua liderança, o autor define "interesse nacional", ao longo da década de 1990, da seguinte forma: "Mantener la independencia, soberanía, autodeterminación y seguridad de la nación cubana, su capacidad de darse un gobierno popular, democrático y participativo propio basado en sus tradiciones, con un sistema económico-social próspero y justo, y que, a su vez, le permita proteger su identidad cultural y sus valores sociopolíticos y proyectarlos en la arena mundial con un nivel de protagonismo acorde a sus posibilidades reales como miembro efectivo de la sociedad internacional" (idem, p. 17).

Apesar do reconhecimento de que o conceito de interesse nacional é controverso e determinado historicamente, podemos destacar que a proposta do autor é interessante porque nos permite identificar de maneira mais clara, e em concordância com o pensamento da liderança cubana, a sua importância para a política externa do país ao longo da década de 1990. Sendo assim, podemos identificar claramente seus objetivos, apontando que o elemento determinante do interesse nacional redefinido foi: "[...] a tenor con su interés nacional, neutralizar y revertir la tradicional política norteamericana de reimplantar su hegemonía sobre la isla, sin hacer concesiones de principio en torno a la soberanía, la autodeterminación, el modelo socialista cubano y su política exterior" (idem, p. 21).

Ou seja, trata-se de afirmar os mecanismos internos de construção e consolidação do regime, assim como desenvolver uma política externa que contribua com tal objetivo, procurando superar os problemas impostos pelo conflito com os EUA e o questionamento de seu modelo político.

De uma forma mais precisa, o embaixador de Cuba no Brasil, ao demonstrar as raízes e a atuação da política externa cubana, procura enfatizar que, 
diante das modificações do cenário internacional no inicio dos anos 1990, "Cuba precisava e precisa de três elementos básicos (antes garantidos pela relação existente com a comunidade dos países socialistas): "capital, mercados e tecnologia" (Sánchez-Parodi 1998, p. 164). Dessa forma, podemos constatar que a liderança cubana procurou redefinir os seus objetivos fundamentais, afirmando a sobrevivência e a inserção, como elementos fundamentais de sua política e como forma de superar os desafios que o país enfrentou.

Além disso, tal afirmação (juntamente com os principais documentos que orientaram as mudanças internas) evidencia que a política externa cubana na década de 1990, foi marcada por um processo, ainda que incompleto, de "desideologização", que ocorria no âmbito interno, e a adoção de uma postura pragmática, considerando que a mesma deveria contribuir para a superação das dificuldades econômicas e seria conduzida, desde então, de uma forma pacífica e formal, evitando ações que pudessem acentuar a política americana e minimizar o apoio de outros países para a superação do isolamento políticodiplomático e a inserção econômica. Além disso, aponta para a centralidade, agora renovada, da busca de integração com os países latino-americanos, que no âmbito econômico tornou possível uma maior aproximação com os países do Caribe e de toda região, ampliando o comércio bilateral e o acesso a capitais.

Finalmente, cabe enfatizar que tal política seria conduzida a partir da observância das leis e do direito internacional, o que conduziu a um maior ativismo nos fóruns multilaterais e o desenvolvimento de estratégias de reforço na confiança recíproca em relação aos países da região e aos parceiros potenciais. Dessa forma, a liderança cubana desenvolve uma política externa que possa atingir os objetivos básicos apontados anteriormente, procurando com isso garantir recursos que pudessem contribuir para a sua sobrevivência e uma inserção adequada do país no novo contexto internacional (Salazar 1997; Altmann 2001; Pisani 2002; Alzugaray 2003).

Ao longo da década de 1990, o Estado cubano conseguiu desenvolver uma política externa coerente e unificada. Comportando-se como um ator racional, o país soube definir adequadamente seus interesses fundamentais e desenvolver uma política consequente com os mesmos, o que não significa a inexistência de tensões e a realização de todos os seus objetivos, como destacaremos posteriormente. $\mathrm{O}$ que procuramos acentuar é que a liderança cubana conseguiu manter a unidade internamente, apesar do aumento de organizações que criticavam o regime, e, principalmente, no desenvolvimento de sua política externa.

Em suma, como também aponta Domínguez (2003), apesar do impacto profundo que representou o fim dos laços com os países socialistas, que reduz brutalmente o setor externo cubano, este apresenta uma tendência à recomposição, embora sem recuperar os valores artificiais do período anterior. Mesmo assim, segundo ele, impressiona a diversificação das relações econômicas internacionais de Cuba no final da década de 90, conforme a tabela 2, a seguir, que resume, de forma adequada, as análises que destacamos anteriormente:

A tabela 2 revela-nos alguns indicadores interessantes. Em primeiro lugar, houve uma queda evidente, denominada por Domínguez (2003) de "negativa", pois ocorreu uma distribuição do comércio exterior cubano sem o aumento adequado no valor das transações; sendo assim, ocorreu um aumento considerável das exportações para Canadá e Holanda e, inversamente, aumentaram-se as importações de Canadá, México, Venezuela, Espanha, França e Itália. Po- 
Tabela 2 - Indicativos de diversificação das relações econômicas internacionais

\begin{tabular}{lcccc}
\hline Transações & Primeiro sócio & $\%$ & Segundo sócio & $\%$ \\
\hline Exportações & Rússia & 23 & Holanda & 13 \\
Importações & Espanha & 18 & Venezuela & 13 \\
Turismo & Canadá & 17 & Alemanha & 11 \\
Dívida & Japão & 19 & Argentina & 14 \\
Investimentos & Espanha & 23 & Canadá & 19 \\
\hline
\end{tabular}

Fonte: Domínguez (2003, p. 455).

rém, ocorreu um aumento do déficit comercial com esses países, aumentando, consequentemente, a dívida cubana com os mesmos. Além disso, deve-se destacar a importância econômica assumida por três países americanos: Canadá, nos setores de turismo e inversão; Argentina, na gestão da dívida cubana; Venezuela, em importações. Cabe destacar ainda, conforme o autor, o caso do México, que é o sexto em importações e o sétimo país mais importante em relação ao turismo e à gestão da dívida. Finalmente, essa diversificação econômica explica-se por fatores específicos de cada atividade, bem como pela estratégia geral adotada pela liderança cubana no sentido de evitar a excessiva dependência de um só país, privilegiando sócios múltiplos em vez de um único. Isso significa a proliferação de sócios múltiplos como um instrumento de proteção e defesa dos interesses da liderança do país, que se constitui em uma das inovações mais importantes do período posterior à Guerra Fria. Como aponta Domínguez (2004b, p. 283): "En resumen, la evolución del comercio internacional de Cuba muestra el impacto del desplome económico y la pérdida de las subvenciones soviéticas. Cuba diversificó sus socios comerciales de forma considerable, especialmente en lo relativo a la importación de bienes. En líneas generales, las relaciones comerciales cubanas con diversos países de la Unión Europea, Canadá, México y China parecían sólidos y firmes. Rusia seguía siendo el principal mercado de exportación, y por ello una fuente potencial de inestabilidad. En particular, las relaciones comerciales con Canadá, Francia, Italia, España y México constituían una réplica a Estados Unidos".

O objetivo central da política externa cubana tem sido, mais do que nunca, garantir a sobrevivência do regime em suas dimensões fundamentais. Tal estratégia pode ser compreendida na adequação dos seguintes objetivos, apontados por Domínguez (2003): (i) manter os mecanismos básicos da estrutura política e institucional, resistindo à pressão externa para a adoção de mecanismos democráticos formais; (ii) fomentar uma abertura de empresas internacionais, de investimentos ou comerciais, porém proibindo o desenvolvimento legal de empresas cubanas; (iii) a reativação do nacionalismo interno como instrumento de coesão e mobilização, considerando as posições do governo americano e da oposição aí instalada; (iv) manter a prioridade de sobrevivência do regime político, mesmo diante da deterioração das relações políticas e econômicas com outros países ou do sacrifício de um desenvolvimento mais acelerado, porém mais desigual (idem, p. 525).

Como apontam Salazar (1997) e Alzugaray (2003), ocorre também uma ampliação dos atores institucionais envolvidos na elaboração e na execução da política exterior cubana sem afetar, porém, a unidade de atuação. Prova disso têm sido o relevo de figuras históricas, o fortalecimento da Chancelaria ${ }^{6}$ e a participação de atores institucionais vinculados à execução das relações econômicas internacionais, como o Ministério de Inversão Estrangeira e Colaboração Econômica. Em relação ao primeiro, cabe destacar o desenvolvimento de um serviço extremamente profissionalizado, com funcionários que possuem
${ }^{6}$ Objeto de preocupação de Raul Roa desde o início da Revolução, a profissionalização dos serviços diplomáticos é cada vez mais evidente, inclusive com a criação e o desenvolvimento do ISRI (Insti- 
tuto de Relações Internacionais), ligado ao MINREX. Para uma compreensão das atividades do instituto e a formação de uma burocracia ligada ao serviço diplomático, ver a página do mesmo na internet: www.isri.cu (acesso em 16.jan.2014) ou do MINREX http://www.cubaminrex.cu/ (acesso em 16.jan.2014). uma ampla formação e conhecimento em diversas áreas, capazes de responder ativamente aos questionamentos que o país enfrentou em determinados fóruns. Para tanto, modernizou-se a estrutura do Ministério de Relaciones Exteriores (MINREX) e sua capacidade de responder a essas e outras demandas, gerando uma maior publicidade das atividades externas do país e, principalmente, uma maior visibilidade de suas posições. Vale ressaltar que tal diplomacia atua, de modo eficaz, tanto em fóruns oficiais, em reuniões bilaterais ou nos organismos multilaterais, como em fóruns de organizações voltadas à crítica à globalização. Tal ação tornou possível a ampliação das relações diplomáticas do país que, mesmo diante do bloqueio americano e do questionamento de seu modelo político, estendem-se a cerca de 180 países, conforme dados do próprio ministério (idem).

Também as Forças Armadas Revolucionárias (FAR) tornaram-se um ator relevante, embora por outras razões. Isso ocorre pela desmilitarização da atuação externa do país, com o retorno, já assinalado, das tropas cubanas estacionadas na África e na América Latina, e a afirmação de uma política pacífica e construtiva em relação aos conflitos que o país participou em décadas anteriores. Os motivos de tal retirada são (i) de ordem política, desenvolvendo uma imagem pacífica e não belicista e gerando um novo tipo de relacionamento diplomático, em que se destacam as questões sociais e (ii) de ordem econômica, em virtude de a dificuldade de sustentar um contingente relativamente elevado de soldados em regiões distantes gerar um custo elevado que não podia mais contar com o apoio soviético. As FAR passaram a atuar nos diversos setores da economia cubana, desde fazendas exportadoras de cítricos até no setor de turismo, tornando-se um importante ator na inserção internacional e reestruturação econômica do país (Caroit 2006).

No entanto, o principal desafio da política externa cubana na década de 1990 continuou sendo a relação conflituosa do país com os EUA e suas consequências, apontada como a razão fundamental do isolamento a que o país viuse submetido e como o elemento fundamental para a compreensão da atuação internacional do país ao longo da década (Alzugaray 2003; Domínguez 2004b).

A essência do conflito entre Cuba e EUA, como aponta Moráles Dominguez (2004), deriva dos fatores históricos, desde o processo de independência de Cuba, e são marcados pelo que o autor define por "fator emocional" como causa fundamental desse conflito. Sendo assim, tal fator pode ser explicado pela emergência, ainda no processo fundacional dos EUA, de que Cuba seria, cedo ou tarde, uma extensão natural do território americano, substanciada na "teoria da gravitação política", mais conhecida por "doutrina da "fruta madura" que se transformou em uma concepção geopolítica apontando que, de uma forma ou de outra, o país seria incorporado à influência norte-americana (idem, p. 165-168). Dessa forma, como também demonstra Hernández (1987), a "lógica de fronteira" é o elemento fundamental para a compreensão das relações entre esses países, modificando-se nas formas como o conflito é realizado ao longo da história, desde o momento de independência de Cuba até as diferentes faces do conflito ao longo do ciclo revolucionário, mas cuja essência permanece.

Além disso, o questionamento da comunidade internacional, em torno de determinados aspectos e ações do regime cubano e sua dinâmica pendular, intensa em certos momentos, constitui-se no outro desafio fundamental que o país enfrenta. 


\section{Conclusões}

Ao longo da década de 1990, Cuba foi tecendo uma rede de apoios no plano bilateral e multilateral que permitem afirmar que a ilha já não está marginalizada no contexto internacional. Se no início dessa década parecia impossível que a ilha pudesse sobreviver, no início do século XXI a reflexão caminha para averiguar as possibilidades reais de manter os êxitos sociais e, ao mesmo tempo, criar as condições para competir em um mundo globalizado.

Sendo assim, podemos apontar que a inserção internacional de Cuba a partir de 1990 foi dificultada pelas insuficiências da economia cubana e pela persistência de um regime que enfrenta críticas de parte da comunidade internacional. Apesar disso, o país conseguiu diversificar suas relações econômicas internacionais entre vários sócios em diferentes esferas e assim reduzir, pela primeira vez, a dependência que orientou suas relações desde a conquista de sua soberania, no final do século XIX. Além disso, manteve um papel de protagonista nos processos de pacificação de lutas guerrilheiras no continente e no seu ambiente geográfico mais próximo. O país também conseguiu angariar apoios contra a política e o embargo americanos, atuando de forma eficaz na distinção deste ato, com a necessidade de abertura e liberalização do regime. E quando teve de escolher, o governo cubano sacrificou suas boas relações políticas e econômicas para impedir qualquer pressão externa em seus assuntos domésticos, principalmente no que se refere à democracia e direitos humanos.

Nesse sentido, Alzugaray (2003), embora de maneira engajada, considera que Cuba obteve mais êxitos que fracassos em sua política externa ao longo da década de 1990. Entre os primeiros, destacam-se a manutenção da soberania, da independência e da capacidade de autodeterminação, que possibilitaram ao país iniciar sua recuperação econômica e ampliar os laços com a comunidade internacional por meio da participação em organismos e fóruns multilaterais. Manteve a capacidade de defesa, e mesmo com a ausência da proteção soviética, o país foi capaz de defender-se e possibilitar uma incorporação de suas forças armadas nos desafios internos e econômicos que o país enfrentava.

Apesar disso, reconhece-se que dois problemas ameaçam a continuidade desses avanços. Por um lado, o fortalecimento do bloqueio americano e a dificuldade de encontrar-se um modus vivendi com o país que seja razoável para ambos os lados, dificultando assim a normalização das relações com a superpotência restante o que, obviamente, comporta riscos. Além disso, a crítica da comunidade internacional ao sistema político cubano acaba gerando um desgaste da imagem do país, implicando novos riscos de isolamento e de conflito com a comunidade internacional. A superação desses desafios, efetivamente, possibilitará um balanço definitivo de sua política externa e a vigência de uma inserção estável e adequada, ou o isolamento na nova ordem internacional do século XXI.

Marcos Antonio da Silva (marocam@terra.com.br) é Doutor em Integração da América Latina pelo PROLAM/USP e professor de Ciência Política da Universidade Federal da Grande Dourados (UFGD).

Guillermo A. Johnson (guijohnson@uol.com.br) é Doutor em Sociologia Política pela UFSC e professor de Ciência Política da Universidade Federal da Grande Dourados (UFGD).

Anatólio Medeiros Arce (anatolio.arce@r7.com) é doutorando do programa de pós-graduação em História da Universidade Federal da Grande Dourados (UFGD). 


\section{Referências}

Alfonso, H.D., 1998. Cuba: significado e importância das mudanças. Política Externa, 7(2), pp. 127-146.

Almendra, C.C., 1998. A situação econômica cubana diante da queda do Leste Europeu. In O. Coggiola, ed. Revolução Cubana: história e problemas atuais. São Paulo: Xamã.

Altmann, W., 2001. México e Cuba: revolução, nacionalismo e política externa. São Leopoldo: Unisinos.

Alzugaray, C., 2003. La política exterior de Cuba en la década de 90: intereses, objetivos y resultados. Política Internacional, 1(1), pp. 14-32.

Ayerbe, L.F., 2004. A revolução Cubana. São Paulo: UNESP.

Bandeira, L.A.M., 1996. Cuba: do socialismo dependente ao capitalismo. Revista Brasileira de Política Internacional, 39(1), pp. 5-18.

1998. De Martí a Fidel: a revolução cubana e a América Latina. Rio de Janeiro: Civilização Brasileira.

Caroit, J.M., 2006. Exército cubano controla 322 empresas. Folha de S. Paulo, n. 28 249, Caderno Mundo, p. A15, 9.ago.

Domínguez, J.I., 2003. Cuba en las Américas: ancla y viraje. Foro Internacional, 43(3), pp. 525-549. . 2004a. El sistema político cubano en los noventa. In V. Bobes \& R. Rojas, eds. La transición invisible. Ciudad de México: Océano.

2004b. La política exterior de Cuba y el sistema internacional. In J. Tulchin \& R. Espach, eds. América Latina en el nuevo sistema internacional. Barcelona: Bellaterra.

Hernández, R., 1987. La lógica de la frontera en las relaciones EUA-Cuba. Cuadernos de Nuestra América, 4(7), pp. 6-54.

Ikenberry, G.J., 2002. A ambição imperial. Política Externa, 11(3), pp. 22-38.

Mesa-Lago, C., 1998. Hacia una evaluación de la actuación económica y social en la transición cubana de los años noventa. América Latina Hoy, 18, pp. 19-39.

Moráles Dominguez, E., 2004. Cuba - EUA: las esencias de una confrontación. Cuadernos de Nuestra América, 17(33), pp. $165-188$.

Pisani, M.E., 2002. Política exterior de la revolución cubana. La Habana: Ciencias Sociales.

Sánchez-Parodi, R., 1998. Raízes e atuação da política externa cubana. Política Externa, 7(2), pp. 153-167.

Sader, E., 2001. Cuba: um socialismo em construção. Petrópolis: Vozes.

Salazar, L.S., 1997. Cuba: ¿aislamiento o reinserción en un mundo cambiado? La Habana: Ciencias Sociales. 2000. El siglo XXI: posibilidades y desafíos para la revolución cubana. La Habana: Ciencias Sociales.

Sartre, J-P., 1986. Furacão sobre Cuba. $5^{\text {a }}$ ed. Rio de Janeiro: Editora do Autor.

\section{Outras fontes}

CEPAL, 2000. La economia cubana. Ciudad de México: Fondo de Cultura Económica.

ISRI, 2014. El sítio del ISRI. Disponível em: http://www.isri.cu/. Acesso em: 16.jan.2014.

MINREX, 2014. Sitio Oficial del Ministerio de Relaciones Exteriores de Cuba. Disponível em: http://www.cubaminrex.cu/. Acesso em: 16.jan.2014.

\section{ABSTRACT}

This paper analyzes the Cuban foreign policy in the 90s, afther collapse of the Soviet Bloc, which led the country to the most serious economic crisis in its recent history and a relative internacional isolation, elements that were decisive to their internacional insertion. Based on this indicates that its internacional rehabilitation is established on the assertion of national sovereignty, the expansion of the actors involved in the formulation and implementation of such a policy in search of new partners leading to a pendulum international position and the development of social diplomacy. This research was conducted by gathering information and literature review, as well as data indicating the country's economic situation and its international insertion, combining elements of quantitative with qualitative analysis. The initial hypothesis is based on the reorientation of Cuban foreign policy, considering the end of Soviet Bloc, and their reintegration, even though strained, determined by the internal crisis and the new international context. The data collection was possible through diligenses in situ and in portals and publications of organizations such as ECLAC (Economic Commission for Latin America) and ONEI (National Office of Statitics and Information), as well authors dedicated to the topic. Through critical and comparative analysis of such data and information sets out the core variables and elements that allow the understanding of Cuban foreign policy in the mentioned period. This work demonstrates that Cuban foreign policy was the result of the interaction between domestic factors, the economic and social crisis that the country faced, and international factors. Moreover, points out that there was a reorientation of Cuban foreign policy, with the development of new strategies and partnerships for international reintegration. Finally, demonstrates that policy achieved a relative success, as it allowed a partial economic recovery and maintenance of the system. The article contributes to the knowledge of the internal reality and the international insertion of Cuba in the new internati- 
onal context, relatively ignored aspects in Brazilian academy and it provides new elements for understanding the determinants of foreign policy aspects of the States in the context of globalization.

KEYWORDS: Foreign Policy; Cuba; Social Diplomacy; Constraints; Internacional Insertion 